\title{
Planejamento e ordenamento territorial do Estado de Roraima: utopia ou realidade?
}

\author{
Territorial planning of Roraima state: utopia or reality?
}

Rozane Ignácio ${ }^{1}$, Edson Vicente da Silva ${ }^{2}$, Thiago Morato de Carvalho ${ }^{3}$,
Carmem Lucia Rosa da Silva ${ }^{4}$

1 Coordenação de Direito/UERR, Brasil. E-mail: rozanerr@gmail.com

2 Departamento de Geografia/UFC, Brasil. E-mail: cacauceara@gmail.com

3 Departamento de Geografia/UFRR, Brasil. E-mail: thiago.morato@ufrr.br

4Centro de Educação/CEDUC/UFRR, Brasil. E-mail: carmem.rosa@ufrr.br

RESUM 0: Este estudo enfoca a importância de se realizar o zoneamento ecológico econômico para o desenvolvimento sustentável e seu embasamento na legislação brasileira, abordando conceitos de gestão territorial. Foram abordados marcos da legislação federal, relacionados à preservação e conservação do meio ambiente, e da implementação de políticas voltadas ao planejamento e ordenamento territorial. Apos o ser abordado um panorama geral para 0 Brasil, apresentamos a situação em que se encontra o zoneamento ecológico econômico do Estado de Roraima, através de um levantamento de registros na impressa local e de estudos já realizados pelos órgãos públicos.

Palavras-chaves: Legislação; Políticas de gestão territorial; Zoneamento Ecológico Econômico; Brasil, Roraima.

\begin{abstract}
This study focuses on the importance of conducting economic ecological zoning for sustainable development and its foundation in the brasilian legislation, addressing concepts of territorial management. Were addressed landmarks of federal legislation related to preservation and environmental conservation, and the implementation of policies to territorial management. After being approached an overview for Brasil, presented the situation in which it is economic ecological zoning of the Roraima state, through a survey of records in the local press and studies carried out by public institutions. Keywords : Legislation; Territorial management policies; Ecological Economic Zoning; Brasil; Roraima.
\end{abstract}

Sumário: 1. Introdução - 2. Políticas de Gestão Territorial, Território e Governança Territorial - 3. Retrato das Políticas de Planejamento e Ordenamento Territorial no Brasil - 3.1 Principais Marcos da Legislação Federal Relacionados ao ZEE - 4. Zoneamento Ecológico Econômico do Estado de Roraima - 5. Considerações Finais - Referências.

\section{INTRODUÇÃO}

O Brasil é uma republica federativa formada pela união de 26 estados federados que

Planeta Amazônia: Revista Internacional de Direito Ambiental e Políticas Públicas 
possuem autonomia administrativa para realizar o seu planejamento e ordenamento territorial. Desta forma, o planejamento urbano é uma atribuição da administração pública e envolvem questões econômicas, físico-territoriais, financeiras, políticas, socioambientais, sendo imprescindível a compreensão do ordenamento do espaço de nossas cidades para que as políticas de gestão urbana possam ser implantadas respeitando as áreas de preservação permanentes e valorizando os aspectos sociais da propriedade urbana visando agregar os interesses das comunidades envolvidas.

O estado de Roraima foi criado em 1988, com a promulgação da Constituição Federal e segundo Carvalho et al. (2016) a característica marcante da região de Roraima é a sua vegetação constituída por áreas abertas e fechadas. Do ponto de vista geomorfológico o relevo destas áreas é composto por diferentes associações de unidades agradacionais e denudacionais, com altitudes variando entre 1000 metros na região serrana de fronteira com a Venezuela, até 80 metros na bacia de Boa Vista, onde está encaixada a maior porção de áreas abertas em contato com a Guiana (CARVALHO, 2014).

Roraima pode ser compartimentado em três grandes unidades: o norte um sistema florestado de serras divisoras dos territórios brasileiros e venezuelanos, ao sul e oeste as matas que se conectam com as matas do rio Negro, a leste um complexo de as áreas abertas, 0 lavrado (VANZOLINI; CARVALHO, 1991; MORAIS; CARVALHO, 2015). Franco et al., (1975) categorizaram a região de Roraima em cinco unidades morfoestruturais: Planalto Sedimentar Roraima, Planalto do Interflúvio Amazonas-Orinoco, Planalto Dissecado Norte da Amazônia, Planaltos Residuais de Roraima e Pediplano Rio Branco-Rio Negro.

Sobre a hidrografia regional Carvalho (2014) a caracteriza como um importante sistema modelador destes ambientes paisagísticos de Roraima, dissecando o relevo na direção predominante norte-sul e pode ser caracterizada como autóctone no geral - os rios do domínio amazônico, no geral, são predominantemente alóctones.

Figura 1: Localização Geográfica do Estado de Roraima.

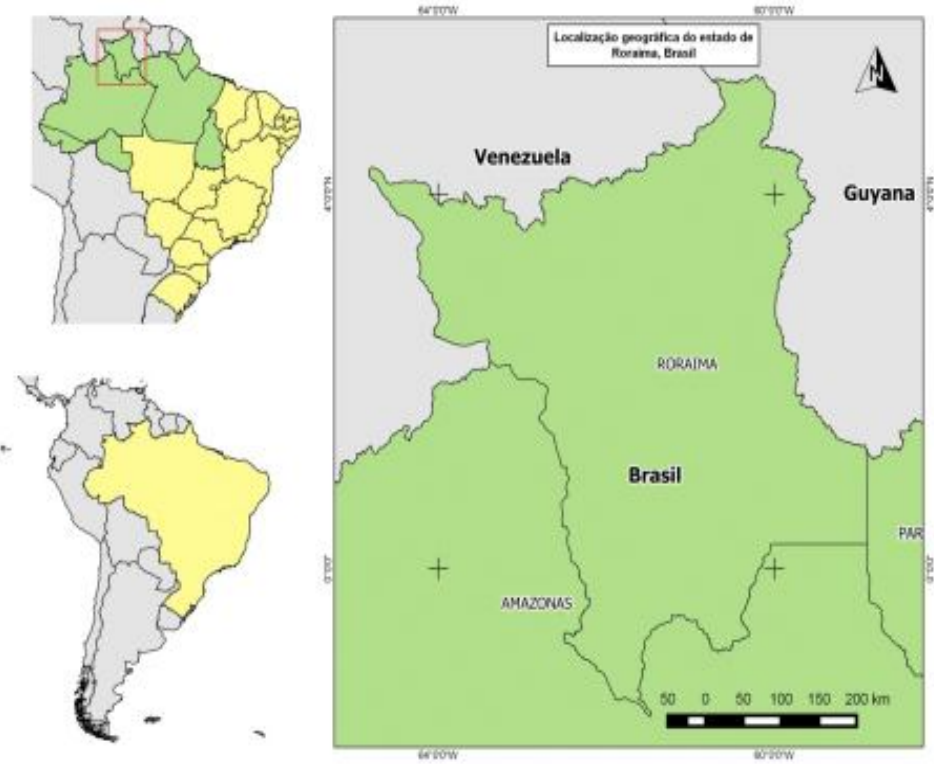

Fonte: M M A/FUNAI, 2015. Elaboração: Souza, 2015. 
O sistema fluvial roraimense é influenciado ao norte e noroeste pelas serras Parima e Pacaraima, divisoras de águas que drenam para o rio Orinoco. Por exemplo, o rio Orinoco nasce na Serra Parima, parte situada a noroeste de Roraima, e se desenvolve na Venezuela; os rios Maú, Cotingo, Panari e Uailan nascem na região das serras do Monte Roraima e drenam para os rios Tacutu e Branco. Na porção noroeste, nas proximidades das Serras Parima e Imeniaris, nascem os rios Parima e Auari, os quais formam o rio Uraricoera, na Serra Uafaranda. 0 Uraricoera corre para leste e se junta ao rio Tacutu (fronteira Brasil-Guiana em quase toda a sua extensão), o qual nasce na região da Serra Wamuriaktawa na Guiana e corre de sul para norte numa fossa tectônica (graben). Ambos os rios vão formar o rio Branco, que corre para o sul e se une ao rio Negro na sua margem esquerda (CARVALHO, 2015; CARVALHO;M ORAIS, 2014).

A gestão desse território é extremamente complexa e a criação e implantação do Zoneamento Econômico Ecológico seria a solução mais viável para gerir esses conflitos, oriundos da institucionalização do Estado de Roraima que, em boa parte, foi construído com base em: Decretos Federais e portarias do M inistério da Justiça e FUNAI - Terras Indígenas; Leis e Decretos Federais e Estaduais - Unidades de Conservação ou áreas ambientais; Memoriais descritivos - áreas militares; Portarias - áreas dos projetos de assentamento do INCRA; Decreto $n=6.754 / 2009$ - terras do Estado em processo de transferência, reguladas pela Lei $n$ 으 $10.304 / 2001^{1}$.

Esta é uma pesquisa bibliográfica que buscou, através de um arcabouço teórico sobre território, gestão e governança discutir as implicações dos zoneamentos ecológicos e econômicos instituídos no Brasil e mais especificamente em Roraima. Esse levantamento foi complementado pela indicação da legislação vinculada às políticas de ordenamento territorial no Brasil e que direcionam as construções dos zoneamentos ecológicos e econômicos do Brasil. Para subsidiar as discussões, realizou-se um levantamento de registros na impressa local que se referem à temática e aos entraves que o processo tem encontrado em Roraima. Esses dados e informações agrupam-se na análise visando atender ao objetivo de analisar o planejamento e ordenamento territorial do Estado de Roraima.

\section{POLÍTICAS DE GESTÃO TERRITORIAL, TERRITÓRIO E GOVERNANÇA TERRITORIAL}

Para entendermos melhor como se realiza a política de gestão territorial faz-se necessário abordar alguns aspectos conceituais acerca dos termos território, governança e gestão territorial.

0 território possui vários significados e é utilizado em diversas áreas do conhecimento, mas ficaremos com a conceituação contemporânea de território que considera a configuração de poder entre os atores que, direta ou indiretamente, atuam em um dado espaço. Os conceitos de escala ampliam ou reduzem os limites territoriais aos limites do espaço construído por cada sistema de poder.

${ }^{1}$ Universidade Federal de Roraima. Disponível em: < http://ufrr.br/mepa/phocadownload/cartilha\%20zeerr\%20-\%20versao\%20final\%20_1_.pdf>

Planeta Amazônia: Revista Internacional de Direito Ambiental e Políticas Públicas 
Em decorrência das configurações assumidas por esse processo, se manifestam identidades sociais relacionadas ao território considerado sendo que, geralmente, a identidade prevalecente é aquela retratada pela configuração hegemônica de poder ${ }^{2}$.

A noção de território implica na compreensão da ideia de espaço. 0 espaço é o patrimônio natural existente em uma região definida. 0 território emerge da ocupação do espaço, pela sua transformação e pelo ordenamento orientado pela configuração de poder dentro dos seus limites (RAFFESTIN, 1993).

O território surge, portanto, como resultado de uma ação social que, de forma concreta e abstrata, física e simbolicamente, se apropria e ocupa um espaço transformando-0. 0 território que resulta dessa ação surge, portanto no contexto de um processo de construção social (FLORES, 2006).

Segundo Flores (2006) o território aparece como um elemento de projeção de identidades e culturas, de poderes e soberanias, de disputas e alianças, de vidas e trabalhos, de tradições e transformações, que envolvem seus integrantes em múltiplas redes que se conectam no tempo e espaço da territorialidade multiescalar. Mas também como a imagem concreta de um poder derivado do Estado, como uma da unidade política administrativa com relativa autonomia legalmente determinada.

Para Santos (1985), a formação do território é externa ao próprio território, a periodização da história é o que define o que será o território, como ele será organizado e como ele se configurará em suas diversas dimensões. 0 autor distingue espaço de território, que denomina como "configuração territorial" e o define como "o todo".

0 espaço é a "totalidade verdadeira" (e concreta) que resulta da interação entre a configuração territorial (território), a paisagem (natureza) e a sociedade. Para uma sociedade só se torna concreta através de seu espaço. A totalidade é formada por instâncias ou estruturas (econômica, jurídico - política e ideológica), e o espaço seria a quarta instância, colocando-se como uma estrutura subordinada e subordinante, um fator social e não apenas reflexo social. Ou seja, se o espaço é resultado da ação humana, e ele é reflexo e condição da sociedade. Então, se temos uma sociedade desigual, o espaço será desigualmente ocupado, distribuído e significado (SANTOS, 1985).

Um território requer a gestão e esta, para tal, necessita de instrumentos. A gestão territorial está presente tanto no ordenamento quanto no desenvolvimento, embora cumpra, idealmente, papéis diferentes em cada um deles. Enquanto ao ordenar ela exerce um poder soberano de Estado, ao desenvolver exerce um papel subsidiário de orientar e apoiar empreendimentos dos diversos setores da sociedade e do próprio Estado. Em termos científicos, a gestão territorial é composta por três campos temáticos: análise, modelagem e planejamento territorial (BARRAGÁN, 1993).

Para entendermos como se realiza a gestão territorial é preciso analisar a questão da governança territorial, já que esta só tem sentido quando se esvai a capacidade do Estado de posicionar-se como gerador de desenvolvimento, passando a discutir modelos alternativos de

${ }^{2}$ Gestão Territorial. Visões e significados. Disponível em: বhttps://www.academia.edu/2052742/Gest\%C3\%A 30_Territorial_Vis\%C3\%B5es_e_significados.

Planeta Amazônia: Revista Internacional de Direito Ambiental e Políticas Públicas 
gestão publica. No Brasil, em 1985, após o final do governo militar, houve uma mudança gradativa na forma de administrar o Estado, havendo ainda resistência dos políticos mais tradicionalistas em aceitar essa nova administração, pois era baseada em acordos que atentavam contra a soberania nacional.

Os seus sucessores no Executivo renderam-se ideologicamente às racionalidades do consenso, no entanto, muitas medidas previstas não puderam ser tomadas, pois dependia de decisões do Legislativo que aguardava por uma nova Constituição para dar os rumos, o que somente viria a acontecer em 1988. O Estado de Roraima surgiu nesse contexto, com a promulgação da Constituição Federal de 1988. Poucos meses depois de promulgada, em 1999, o Executivo apresentava o que viria a ser conhecida como a "operação desmonte" do Estado, este visto como o vilão dos problemas do país, quando uma série de extinções, fusões, descentralizações e delegações de responsabilidades foram efetivados em decorrência, segundo seus mentores, da transferência de poder e de responsabilidades para os demais entes federativos, reduziu significativamente os espaços de atuação do governo federal.

Só aí, então, faria sentido tratar-se de "governança", pois as disposições constitucionais determinavam alterações na ordem de poder entre os entes federativos e, timidamente, entre o Estado e a sociedade civil. Foi o momento do "Estado desenvolvimentista" dar lugar à participação social e, assim, tratar de "governança" ${ }^{3}$.

Pode-se perceber os processos de governança territorial como formas de governo interativo ou sociopolítico, ou seja, acordos estabelecidos entre atores públicos e privados com o fim de resolver problemas e criar oportunidades, já o termo "sistema de governança territorial" pode ser utilizado para referir-se ao conjunto de estruturas em rede, através das quais os atores/agentes e organizações/instituições territoriais atuam no planejamento e consecução das ações voltadas à gestão territorial. No desenvolvimento territorial, as estratégias de governança apostam na capacidade dos espaços públicos conduzirem à construção de acordos entre os atores governamentais e os atores da sociedade civil (DALLABRIDA, 2007).

Na sua concepção mais atual, a "gestão territorial" tem o sentido de ordenar os papéis dos atores na gestão dos processos de desenvolvimento, promovendo a articulação de instrumentos públicos e privados, mediando conflitos de interesses, promovendo a divulgação sobre os projetos em andamento, influindo, assim, na distribuição e uso do poder no âmbito de um dado território, objeto de intervenção de uma ação pública. Após essas considerações acerca dos temas território e governança territorial, analisaremos as políticas de planejamento e ordenamento territorial no Brasil.

\section{RETRATO DAS POLÍTICAS DE PLANEJAM ENTO E ORDENAM ENTO TERRITORIAL NO BRASIL}

Elaborar uma política de gestão territorial para o Brasil é uma tarefa altamente complexa, devido a sua diversidade ambiental, social, econômica e política. No aspecto ambiental, é caracterizado por vários ecossistemas, em estágios de conservação diferenciados; sob o

\footnotetext{
${ }^{3}$ Gestão Territorial. Visões e significados. Disponível em: «ttps://www.academia.edu/2052742/Gest\%C3\%A 30_Territorial_Vis\%C3\%B5es_e_significados.
} 
aspecto social é composto por diferentes grupos humanos, com territorialidades próprias e divergentes entre si. Do ponto de vista econômico, apresenta processos produtivos inconstantes e, em relação ao político, destaca-se a prevalência dos interesses particulares em detrimento dos interesses públicos, tanto na esfera federal, como na estadual e municipal.

Conforme informações apresentadas no Portal do Ministério do Meio Ambiente ${ }^{4}$, 0 Brasil tem se mobilizado para resolver os problemas relacionados com as questões da gestão territorial, pois os governantes possuem vários exemplos internacionais de que o crescimento econômico dissociado da preservação dos recursos naturais gera consequências irreversíveis para to da a humanidade.

M as criar uma política de gestão territorial uniforme, não resolveria o problema, pois as diversas regiões do país possuem características próprias e requerem políticas que respeitem essas especificidades. Desta forma, as politicas de gestão territorial são elaboradas em conjunto com o governo federal, estadual e municipal, visando dinamizar o território, respeitando suas identidades e estimulando ações integradas, visando minimizar as desigualdades nacionais.

Ainda, segundo o Departamento de Gestão Territorial do Ministério do M eio Ambiente, é essencial adotar uma visão estratégica do território nacional para a articulação política e para objetivar metas de crescimento econômico e de combate à desigualdade social, aliada à conservação dos recursos naturais. Deve haver não apenas uma conexão entre a elaboração e a execução de um plano nacional e de planos de desenvolvimento regional e planejamento territorial, pela União, e de planos estaduais e municipais, mas também em relação à atuação dos entes federados na proteção do meio ambiente e na promoção do desenvolvimento e da integração social.

0 planejamento ambiental territorial apresenta relações essenciais com o desenvolvimento regional e com o desenvolvimento do país, de forma mais ampla, condiciona e expressa o desenvolvimento histórico do país, seu desdobramento e redefinição exigem horizontes temporais que não se esgotam no curto prazo. Além disso, como instrumento de regulação das tendências de distribuição de atividades produtivas e equipamentos, diante de objetivos estratégicos e, ainda, como produto de articulação institucional e de negociações entre atores significativos, oferecendo subsídios para enfrentar graves problemas sociais, e servir de base à própria legitimação do Estado ${ }^{5}$.

Visando cumprir com essas metas elencadas pelo M inistério do Meio Ambiente, destacamos a importância do Zoneamento Ecológico Econômico (ZEE), que é um instrumento da Política Nacional do M eio Ambiente, regulamentado pelo Decreto no 4.297/2002 e tem como objetivo viabilizar o desenvolvimento sustentável a partir da compatibilização do desenvolvimento socioeconômico com a proteção ambiental, através do diagnóstico dos meios físico, socioeconômico e jurídico-institucional e do estabelecimento de cenários exploratórios para

\footnotetext{
${ }^{4}$ Ministério do M eio Ambiente. Gestão territorial. Disponível em:〈http://www.mma.gov.br/gestao-territorial/ zoneamento-territorial>

${ }^{5}$ M inistério do M eio Ambiente. Gestão territorial. Disponível em: ‘http://www.mma.gov.br/gestao-territorial/ zoneamento-territorial>
}

Planeta Amazônia: Revista Internacional de Direito Ambiental e Políticas Públicas 
a proposição de diretrizes legais e programáticas para cada unidade territorial identificada, estabelecendo ações voltadas à mitigação ou correção de impactos ambientais danosos porventura ocorridos.

0 mapa e o quadro (figuras 2 e 3) representam o esforço conjunto de técnicos, gestores públicos e segmentos sociais que durante duas décadas se empenharam em muitas negociações políticas para chegarem num consenso sobre os processos de produção da informação referentes aos ZEEs dos Estados da Amazônia Legal, o qual resultou numa base concreta para debate e aprimoramento da gestão territorial na região, sendo instrumento de comando, controle, e de prospecção, capaz de propor alternativas de uso sustentável dos recursos naturais e de aproveitamento das potencialidades sociais e econômicas.

Segundo informações divulgadas no portal do Ministério do Meio Ambiente as bases de informações que permitiram a construção do ZEEs da Amazônia Legal encontram-se em diversas escalas e muitas vezes com nominações diferentes para o mesmo evento.

Os Estados de Rondônia, M ato Grosso, Amapá e Roraima elaboraram Cartas de Zoneamento na escala de 1:250.000. Os Estados do Acre e Tocantins mesclaram áreas em escalas de 1:1.000.000 e 1:250.000. Tocantins também utilizou informações do seu Zoneamento Agro-Ecológico, resultante de uma base de dados na escala 1:250.000.

Figura 2: Mapa integrado dos Zoneamentos Ecológico Econômicos dos Estados da Amazônia.

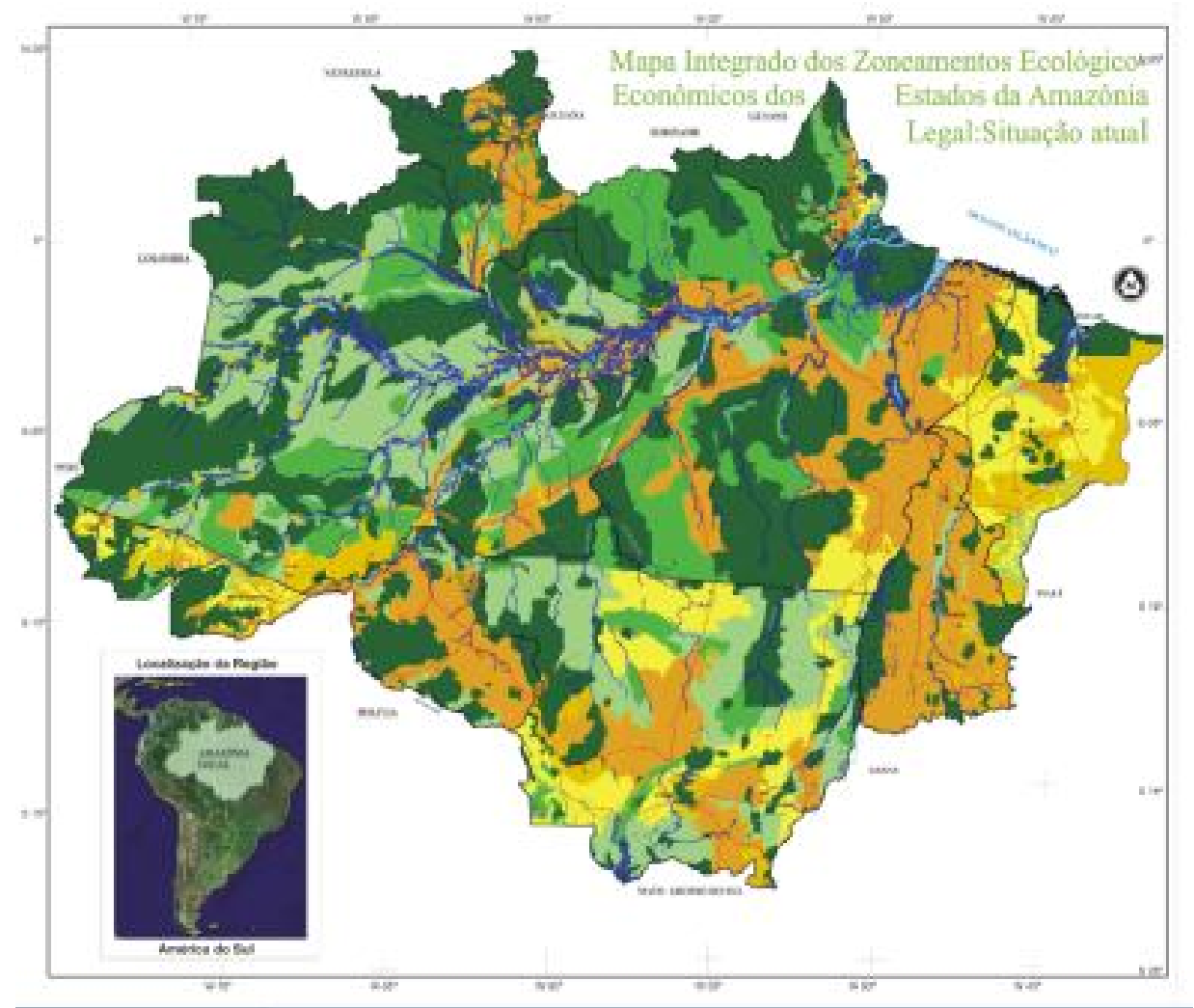

Fonte: M MA/SEDR/DZT/2009. 
Figura 3: Quadro com proposta de legenda para integração dos ZEES estaduais da Amazônia Legal.

\begin{tabular}{|c|c|c|c|}
\hline CATEGORIA & SUBCATEGORIA & CONCEITOS & CARACTERISTICAS \\
\hline \multirow{2}{*}{$\begin{array}{l}\text { (1) USOS } \\
\text { CONSOLIDADOS/A } \\
\text { CONSOLIDAR }\end{array}$} & $\begin{array}{l}\text { (1.1) AREAS COM } \\
\text { ESTRUTURA PRODUTIVA } \\
\text { DEFINIDANA DEFINIR }\end{array}$ & $\begin{array}{l}\text { Áreas consolidadas ou em processo de } \\
\text { consolidaçăo das atividades produtivas } \\
\text { mais dinámicas, que requerem açôs } \\
\text { de manutençâa olou intensificaçáa das } \\
\text { atividades existentes, objetivando a } \\
\text { sustentabilidade ecológica, social e } \\
\text { económica. }\end{array}$ & 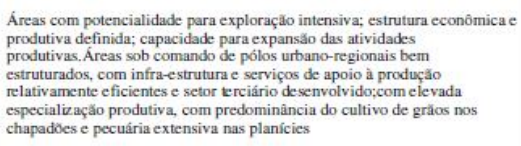 \\
\hline & $\begin{array}{l}\text { (1.2) AREAS A RECUPERAR } \\
\text { EOU REORDENAR }\end{array}$ & $\begin{array}{l}\text { Áreas alteradas ou degradadas por uso } \\
\text { inadequado, requerendo açoes de } \\
\text { recuperaçao ambiontal e/ou } \\
\text { reordenaçao das atividades produtivas. }\end{array}$ & 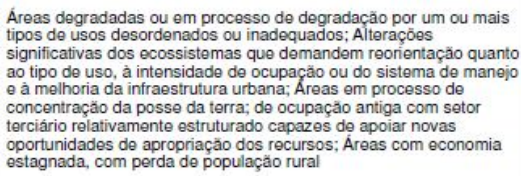 \\
\hline \multirow{2}{*}{$\begin{array}{l}\text { (2) USOS } \\
\text { CONTROLADOS }\end{array}$} & (2.1) ÁREAS FRÁGEIS & $\begin{array}{l}\text { Áreas com fragilidades especificas, de } \\
\text { interesse a manutençáo do estado de } \\
\text { conservaçäo para uso dos recursos } \\
\text { naturais de forma planejada } \theta \text { limitada, } \\
\text { de acordo com normas especiais de } \\
\text { controle. }\end{array}$ & $\begin{array}{l}\text { Áreas com fragilidades naturais especificas; limitadas ofertas de } \\
\text { recursos naturais; vulneráveis às atividades económicas em curso. } \\
\text { Áreas de proteçáo estratégica de recursos hidricos } \theta \text { minerais } \theta \\
\text { vulneráveis à pressấo antrópica }\end{array}$ \\
\hline & $\begin{array}{l}\text { (2.2) ÁREAS COM MANEJO } \\
\text { SUSTENTAVEL }\end{array}$ & 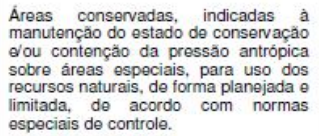 & 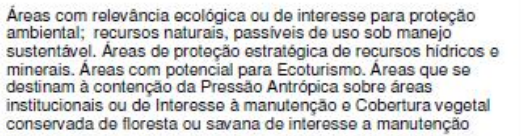 \\
\hline $\begin{array}{l}\text { (3) USOS } \\
\text { ESPECIAIS }\end{array}$ & $\begin{array}{l}\text { (3.1) AREAS PROTEGIDAS } \\
\text { PROPOSTAS }\end{array}$ & $\begin{array}{l}\text { Áreas Legalmente Protegidas, relativas } \\
\text { as Terras Indigenas, de quilombo, de } \\
\text { dominio das Forças Armadas e } \\
\text { Unidades de Conservaçăo existentes e } \\
\text { propostas. }\end{array}$ & $\begin{array}{l}\text { Áreas pertencentes ao Sistema Nacional de Unidades de } \\
\text { Conservacáo- SNUC. Areas sob controle da Fundacăa Nacional do } \\
\text { Indio - FUNAI. Areas de domínio das Forcas Armadas. Areas } \\
\text { propostas pelos Estados para Unidades de Conservaçáo }\end{array}$ \\
\hline
\end{tabular}

Fonte: M MA/SEDR/DZT, 2009.

Os Estados do Pará e Maranhão possuem um Macrozoneamento ao milionésimo. 0 Estado do Amazonas não possui uma carta de Subsídio à Gestão para todo seu território, mas está em processo de discussão na Comissão Estadual de ZEE, apresentando, aqui, uma proposta técnica preliminar ${ }^{6}$.

Desta forma, vimos que o ZEE é um instrumento essencial, já que visa contribuir para racionalizar o uso e a gestão do território, minimizando as ações predatórias e indicando as atividades mais adaptadas às particularidades de cada região, melhorando a capacidade de percepção das inter-relações entre os diversos componentes da realidade e, por conseguinte, elevando a eficácia e efetividade dos planos, programas e políticas, públicos e privados, que incidem sobre um determinado território, especializando-os de acordo com as especificidades observadas.

\subsection{Principais marcos da legislação federal relacionados ao ZEE}

Visando conciliar as difíceis tarefas de realizar o desenvolvimento econômico do país e sua conservação ambiental foi que o governo federal criou leis relacionadas a preservação e conservação do meio ambiente, que posteriormente deram início a implementação das políticas voltadas ao planejamento e ordenamento territorial, dentre as quais destacamos a

${ }^{6}$ Ministério do Meio Ambiente. Disponível em: বhttp://www.mma.gov.br/estruturas/225/_imagens/mapa_ Estados_integrados_225.jpg>

Planeta Amazônia: Revista Internacional de Direito Ambiental e Políticas Públicas 
criação das seguintes leis federais:

1. Lei no 6.938, de 31 de agosto de 1981, que dispõe sobre a Política Nacional do Meio Ambiente (PNMA), seus fins e mecanismos de formulação e aplicação, e dá outras providências. Em seu artigo 9o são relacionados os instrumentos da PNMA, dentre os quais o zoneamento ambiental, posteriormente denominado de zoneamento ecológico-econômico.

2. Lei $n-7.661$ de 16 de maio de 1988, que institui o Plano Nacional de Gerenciamento Costeiro (PNGC) e dá outras providências. No artigo 30 da lei está previsto o zoneamento de usos e atividades na zona costeira.

3. Decreto s/no de 28 de dezembro de 2001, que dispõe sobre a Comissão Coordenadora do Zoneamento Ecológico-Econômico do Território Nacional e o Grupo de Trabalho Permanente para a Execução do Zoneamento Ecológico-Econômico, institui o Grupo de Trabalho Permanente para a Execução do Zoneamento Ecológico-Econômico, denominado de Consórcio ZEE Brasil, e dá outras providências.

4. Decreto № 4.297 de 10 de julho de 2002, que regulamenta 0 art. $9^{\circ}$, inciso II, da Lei $n^{0}$ 6.938, de 31 de agosto de 1981, estabelecendo critérios para o Zoneamento EcológicoEconômico do Brasil - ZEE, e dá outras providências. Contem as bases legais que fundamentam a realização do ZEE, do qual destacamos os artigos $2^{\circ}$ e $3^{\circ}$, po is caracteriza 0 ZEE e estipula o seu objetivo geral.

5. Decreto $\mathrm{n}-5.300$ de 7 de dezembro de 2004, que regulamenta a Lei $n^{0}$ 7.661, de 16 de maio de 1988, que institui o Plano Nacional de Gerenciamento Costeiro - PNGC dispõe sobre regras de uso e ocupação da zona costeira e estabelece critérios de gestão da orla marítima, e dá outras providências. 0 ZEE costeiro é posto, no artigo 70, como um dos instrumentos de gestão da zona costeira, sendo que o anexo I da lei contém um quadro orientador para a obtenção do referido zoneamento.

6. Lei Complementar no 140 de 08 de dezembro de 2011, que fixa normas para a cooperação entre os entes da federação no exercício da competência comum relativa ao meio ambiente, prevista no artigo 23 da Constituição Federal de 1988. De acordo com a LC no 140, constitui ação administrativa da União a elaboração do zoneamento ambiental na escala nacional e regional, cabendo aos Estados elaborar o zoneamento de âmbito estadual, em conformidade com os zoneamentos no nível nacional e regional, e aos municípios a elaboração do plano diretor, observando os zoneamentos existentes.

7. Lei no 12.651 de 25 de maio de 2012, que dispõe sobre a proteção da vegetação nativa; altera as Leis $n^{05} 6.938$, de 31 de agosto de 1981, 9.393, de 19 de dezembro de 1996, e 11.428, de 22 de dezembro de 2006; revoga as Leis $n^{0 \text { - }} 4.771$, de 15 de setembro de 1965, e 7.754, de 14 de abril de 1989, e a M edida Provisória n-2.166-67, de 24 de agosto de 2001; e dá outras providências. 0 ZEE é abordado nos artigos 11-A, 12, 13 e 14 da referida lei.

A criação de todas essas leis demonstra a preocupação dos governantes não só com 0 planejamento e ordenamento territorial do Brasil, mas também com a preservação e conservação dos recursos naturais, o que sem dúvida é um avanço nas políticas públicas, mas ainda requer o envolvimento da sociedade e a valorização do meio ambiente, que mesmo sendo protegido constitucionalmente, ainda é visto como um empecilho ao desenvolvimento eco- 
nômico do país.

\section{ZONEAMENTO ECOLÓGICO ECONÔMICO DO ESTADO DE RORAIMA}

Após a trajetória do governo federal visando efetivar as políticas de gestão territorial e após a criação do Z⿱一EE Nacional, o Estado de Roraima, visando atender as diretrizes nacionais acerca dessas politicas instituiu o Sistema de Planejamento e Ordenamento Territorial do Estado de Roraima, através das Leis Complementares № 143/2009 e № 144/2009, denominado SPOT/RR e constitui-se no principal instrumento orientador de planejamento da ocupação do solo e controle da utilização dos recursos naturais do território do Estado de Roraima, a ser seguido na implantação de planos, programas, projetos, obras e atividades públicas e privadas.

A LC no 143/2009 - SPOT/RR destina o capítulo IV para tratar sobre o Zoneamento Ecológico Econômico do Estado de Roraima - ZEE/RR e traz em seus artigos 90 ao 150 estabelece conceitos, objetivos e as diretrizes para a sua implementação.

Porém, no decorrer desta pesquisa vimos que a institucionalização e instrumentalização do ZEE/RR vêm ocorrendo de forma lenta e gradual e destacamos alguns aspectos relacionados à gestão administrativa do Estado de Roraima que contribuem para a não efetivação desses instrumentos legais, já que desde a criação do Estado de Roraima (1988) as administrações estaduais, se concentraram na organização e manutenção da máquina administrativa; na construção de estradas, escolas, hospitais e redes de distribuição de energia elétrica; com pouca atenção ao planejamento territorial do Estado, tendo como consequência a estagnação do setor produtivo e o PIB é inteiramente voltado ao setor de serviços públicos.

Roraima é um Estado com enormes riquezas minerais, hídricas e um possui um grande potencial para a produção agrícola e agroindustrial; A temperatura em torno de $23^{\circ} \mathrm{C}$ a $33^{\circ} \mathrm{C} \mathrm{e}$ a abundância de água, possibilita a produção primária durante todo 0 ano com produtos que podem abastecer não somente o mercado interno, mas também o nacional; Possui uma posição geográfica e geopolítica estratégica, representando a saída do Brasil para os países caribenhos, como a BR-174 interligando Boa Vista a Manaus com a Venezuela e Guiana; destes para rotas internacionais do mercado mundial. Estes fatos configuram um fator determinante para o desenvolvimento da região. Mesmo com essas riquezas e potenciais, o Estado de Roraima é dependente de recursos da União em mais de $80 \%$ do seu orçamento.

Além da criação de leis estaduais como a do SPOT/RR, o Estado de Roraima adotou algumas medidas no intuito de melhor gerir seu território, tais como programas e órgãos que dariam suporte à implementação do ZEE no Estado de Roraima, destacando-se a criação da Fundação Estadual do M eio Ambiente e Recursos Hídricos - FEM ARH/RR, o Instituto de Amparo a Ciência, Tecnologia e Inovação - IACTI/RR, e o Centro de Geotecnologia, Cartografia e Planejamento Territorial, vinculados à SEPLAN/RR; a criação do Programa Roraimense de Regularização Ambiental das Propriedades e Posses Rurais (RR Sustentável), o Programa de Gestão Integrada e Promoção do Desenvolvimento Sustentável, que abrange as ações de desenvolvimento florestal e gestão de florestas públicas e concessões florestais; e a Lei no 
738/2009 que dispõe sobre a política fundiária rural do Estado de Roraima.

Posteriormente, foi criado o Comitê Gestor de Geotecnologia, Cartografia, Planejamento e Ordenamento Territorial por meio do Decreto no 6.817-E, de 20/12/2005 e o Grupo de Trabalho Permanente para o Detalhamento do ZEE/RR, instituído pelo Decreto $n^{\circ} 11.673$ E, de 04/08/2010.

Em 04 de agosto de 2015 foi publicado o novo Decreto no 19.328-E que criou a Comissão Institucional de Análise do Zoneamento Ecológico-Econômico do Estado de Roraima, além de revogar 0 art. 30 do Decreto $n-6.817-E$, de 20/12/2005, que estipulava os membros do Grupo de Trabalho Permanente para a Execução do Detalhamento do Zoneamento Ecológico-Econômico.

Porém, apesar de todo esse empenho por parte do governo estadual o ZEE/RR ainda não foi implementado e segundo informações divulgadas no site do Ministério do M eio Ambiente o zoneamento do Estado de Roraima encontra-se em revisão, com a participação do Consórcio ZEE Brasil, para sua adequação às diretrizes metodológicas para a elaboração do ZEE. A previsão inicial era que os ajustes seriam concluídos no segundo semestre de 2015, para posterior apresentação do zoneamento à Comissão Coordenadora do Zoneamento Ecológico-Econômico do Território Nacional (CCZEE), porém, recentemente acompanhamos na mídia local que devido a denúncias de irregularidades, a atual gestão resolveu descartar 0 ZEE/ RR elaborado em 2002 e iniciou a elaboração de um novo estudo, o que gerou opiniões controversas.

Segundo informações publicadas no jornal Folha de Boa Vista do dia 07/01/2016 o Governo do Estado criou, por meio de Decreto no 20.328-E de 30/12/2015, uma comissão para apurar certas irregularidades do contrato para a $1^{1}$ a etapa do Zoneamento Ecológico EconômiCO (ZEE) $)^{7}$.

Outra notícia acerca do ZEE/RR foi publicada no Jornal Folha de Boa Vista do dia 16 de dezembro de 2015 e traz a entrevista com Ademir Passarinho, coordenador do ZEE e Alysson Macedo, diretor presidente do ITERAIMA, os quais relatam que para concluir a fase de estudos do Zoneamento Ecológico Econômico (ZEE), a Comissão Institucional do ZEE de Roraima percorrerá o interior do Estado para colher ideias e subsídios. A ideia é realizar oficinas e seminários, a partir da primeira quinzena de fevereiro de 2016, nos municípios de Bonfim, Rorainópolis, São João da Baliza, Pacaraima, Caracaraí e Alto Alegre. A última e maior reunião deverá ser realizada em Boa Vista.

o Zoneamento tem como objetivo ordenar a ocupação do território e definir as áreas protegidas, assim como auxiliar a Fundação Estadual do M eio Ambiente e Recursos Hídricos (FEM ARH) a liberar o licenciamento ambiental e na elaboração de políticas públicas. "É um marco para o desenvolvimento sustentável para o Estado", destacou Passarinho.

Para Passarinho, o ZEE deixou de ser uma "caixa-preta" e hoje funciona com transparência para a população. "A governadora Suely Campos, criou por decreto a comissão, que é composta por 43 membros, sendo eles órgãos públicos estaduais, federais, políticos institu-

\footnotetext{
${ }^{7}$ Jornal Folha de Boa Vista. Disponível em:〈http://www.folhabv.com.br/noticia/Comissao-vai-apurar-indiciosde-irregularidades-em-contrato/ 12858
}

Planeta Amazônia: Revista Internacional de Direito Ambiental e Políticas Públicas 
cionais, sociedade civil organizada. Tem prestação de contas e a participação da sociedade, sendo uma comissão propositiva e consultiva", disse à Folha.

De acordo com o coordenador, Ademir Passarinho, a comissão está firmando termos de cooperação técnica com várias entidades, pois se trata de um estudo técnico complexo, que envolve diversas áreas técnicas como em pedologia, vegetação, aptidão agrícola, antropologia, zonificação, dentre outras e a previsão é que o ZEE esteja pronto em julho de 2016, já que começaram os trabalhos em maio de 2015 e somente cerca de $20 \%$ dos ZEEs anteriores foram aproveitados e ainda estão sendo firmados os termos de cooperação com os órgãos que compõem o Consórcio Nacional, os quais deverão aprovar o ZEE/RR.

Após a finalização do texto do Zoneamento Ecológico Econômico, o Governo do Estado fará projeto de lei e o encaminhará para a Assembleia Legislativa, que aprovará ou não a lei. Em caso de aprovação, a lei será sancionada e o texto encaminhado para a Comissão Nacional do ZEE, onde será analisado tecnicamente pelo Consórcio Nacional do ZEE. Depois de aprovado em Brasília, o ZEE/ RR será divulgado e implementado.

Porém, nem todos coadunam com a opinião do governo estadual de que a melhor saída é a "revisão" do ZEE/RR, e dentre estes, se destaca o posicionamento do ex-vicegovernador e geólogo, Salomão Cruz, que divulgou sua opinião durante o programa Agenda da Semana, da Rádio Folha AM 1020, apresentado pelo radialista Marcelo Nunes, no dia 05 de abril de 2015 e publicada no Jornal Folha de Boa Vista veiculado no dia 06/04/2015, na qual ele afirma que o plano necessário para a instalação do Zoneamento EcológicoEconômico (ZZEE) de Roraima está pronto há 12 anos e o Estado perde anualmente com a demora da instalação do ZEE, destacando ainda os caminhos percorridos até hoje para a efetivação da ZZEE no Estado ${ }^{8}$.

De acordo com Salomão Cruz, o plano foi elaborado em 2003 pelo Serviço Geológico do Brasil (CPRM), mas foi modificado pelo Governo do Estado da época, que somente apresentou o projeto em 2009, quando teve parecer técnico reprovado pelo Conselho Nacional de Zoneamento Ecológico Econômico (CNZEE), órgão que regulamenta a instalação dos ZEEs no País.

Salomão Cruz afirma que por algum motivo, o plano elaborado pela CPRM foi modificado por uma empresa local contratada pelo governo por aproximadamente $\mathrm{R} \$ 1,5$ milhão. $\mathrm{A}$ empresa se limitou a alterações de tópicos dos trabalhos executados pela CPRM. Contudo, não havia necessidade de alterações dos mapas temáticos apresentados em 2003, já que esses mapas continham todas as exigências necessárias para a execução da do ZEE em Roraima, assim foram solicitadas várias modificações no plano refeito, o que acabou paralisando 0 andamento da ZEE no Estado. Ele explicou que para se criar uma ZEE são necessárias três etapas: o mapeamento da área, (realizado pela CPRM e que foi modificado pelo Estado), seguida pela interpretação dos mapas temáticos da etapa anterior (onde o projeto de Roraima foi barrado) feita por técnicos com experiência em zoneamento, resultando na terceira etapa, que une os mapas ao texto e resulta numa peça técnica com o objetivo de nortear o desen-

${ }^{8}$ Jornal Folha de Boa Vista. Disponível em:বhttp://www.folhabv.com.br/noticia/Geologo-afirma-que-Zonea mento-Ecologico-Economico-esta-pronto-ha-12-anos-/5999> 
volvimento sustentado na região.

Conforme Salomão, a instalação do ZEE em Roraima começou em 1999, com recursos da Superintendência da Zona Franca de Manaus (Suframa), no valor aproximado de R\$1,3 milhão, mais a contrapartida do Estado no valor de aproximado de $\mathrm{R} \$ 10$ por quilometro quadrado $\left(\mathrm{km}^{2}\right)$ e esse valor era bem inferior aos cobrados em Mato Grosso e em Rondônia, por exemplo, que era $\mathrm{R} \$ 100$ por $\mathrm{km}^{2}$, uma vez que a CPRM já dispunha da maioria dos dados de campo de mapeamentos anteriores e que é uma empresa pública com experiencia em zoneamentos na Amazônia.

Porém, os anos passaram e em 2012, com a aprovação do novo Código Florestal, ficou estabelecido um prazo de cinco anos para que os Estados elaborassem e aprovassem os seus ZEEs, segundo metodologia unificada, estabelecida em norma federal. Após essa exigência, 0 Governo Federal se dispôs a assessorar os Estados mediante um consórcio chamado Comissão Coordenadora do Zoneamento Ecológico Econômico do Território Nacional (CCZEE), inclusive com apoio técnico de quinze instituições públicas, dentre as quais consta a CPRM . Mas, segundo Salomão, o Governo de Roraima, mesmo com todo o auxílio técnico, nunca utilizou a cooperação técnica e assessoramento disponíveis.

\section{CONSIDERAÇÕES FINAIS}

Constatamos através deste estudo que o planejamento e ordenamento territorial do Brasil e do Estado de Roraima envolve situações complexas e interesses divergentes e a vontade política é fator determinante para a realização desse instrumento, pois não bastam criar leis, órgãos públicos, comissões, se não houver ações conjuntas e integradoras no sentido de concretizar o que preconiza tais leis.

Certas ações políticas nem sempre visam ao bem da coletividade e à preservação do meio ambiente, mas atendem aos interesses particulares, conforme mostram algumas reportagens que tratam sobre a criação do ZEE/RR. Devido a essas posturas não há uma uniformidade de ações, nem um planejamento territorial que perdure além de um mandato de quatro anos, pois cada governante quer contratar a sua equipe técnica, que por sua vez quer fazer um "novo trabalho".

No Brasil as leis são elaboradas, aprovadas e descumpridas, tornando assim o planejamento e ordenamento territorial uma meta "utópica" dos governos federais, estaduais e municipais, já que o crescimento econômico do País não está atrelado à preservação e conservação dos recursos naturais.

A sociedade civil como parceira das ações governamentais, como a implementação do ZEE/ RR, deve se mobilizar e contribuir para que o ZEE/ RR seja legitimado e se torne realidade, cumprindo efetivamente seu objetivo, que é compatibilizar as atividades econômicas e 0 ambiente natural, propiciando qualidade de vida às presentes e futuras gerações. 


\section{REFERÊNCIAS}

BARBOSA, R.I., Campos, C., Pinto., F., Fearnside, P.M. 2007. The Lavrados of Roraima: Biodiversity and Conservation of Brazil's Amazonian Savannas. Functional Ecosystems and Communities, 1( 1):29-41.

BRASIL. Decreto no 4.297, de 10 de julho de 2002. Regulamenta 0 art. 9 , inciso II, da Lei $\mathrm{n}^{\circ}$ 6.938, de 31 de agosto de 1981, estabelecendo critérios para o Zoneamento EcológicoEconômico do Brasil - ZEE, e dá outras providências. Disponível em: বhttp://presrepublica.jus brasil.com.br/legislacao/99889/decreto-4297-02>. Acesso em 10 jan. 2016.

BRASIL. Decreto $\mathbf{n}^{\circ} \mathbf{6 . 7 5 4}$, de 28 de janeiro de 2009. Regulamenta a Lei $n^{0}$ 10.304, de 5 de novembro de 2001, que dispõe sobre a transferência ao domínio do Estado de Roraima de terras pertencentes à União, e dá outras providências. Disponível em: বhttp://www. planalto. gov.br/ccivil_03/_Ato2007-2010/2009/Decreto/D6754.htm>. Acesso em 10 jan. 2016.

BRASIL. Decreto $\mathrm{n}^{-} \mathbf{4 . 2 9 7}$, de 10 de julho de 2002. Regulamenta 0 art. 90, inciso II, da Lei $\mathrm{n}^{0}$ 6.938, de 31 de agosto de 1981, estabelecendo critérios para o Zoneamento EcológicoEconômico do Brasil - ZEE, e dá outras providências. Disponível em: বtttp://www.planalto. gov.br/ccivil_03/decreto/2002/d4297.htm.>Acesso em 10 jan. 2016.

BRASIL. Decreto no 5.300, de 07 de dezembro de 2004. Regulamenta a Lei n- 7.661, de 16 de maio de 1988, que institui o Plano Nacional de Gerenciamento Costeiro - PNGC, dispõe sobre regras de uso e ocupação da zona costeira e estabelece critérios de gestão da orla marítima, e dá outras providências. Disponível em: বhttp://www.planalto.gov.br/ccivil_03/_ato20042006/2004/decreto/D5300.htm>. Acesso em 11 jan. 2016.

BRASIL. Lei no 6.398 de 31 de agosto de 1981. Dispõe sobre a Política Nacional do Meio Ambiente, seus fins e mecanismos de formulação e aplicação, e dá outras providências. Disponível em: ঝttp://www.planalto.gov.br/ccivil_03/Leis/L6938.htm>. Acesso em 10 jan. 2016.

BRASIL. Lei no 7.661 de 16 de maio de 1988. Institui o Plano Nacional de Gerenciamento Costeiro e dá outras providências. Disponível em: বhttp://www.planalto.gov.br/ccivil_03/leis/ L7661.htm>. Acesso em 10 jan. 2016.

BRASIL. Lei no $\mathbf{1 0 . 3 0 4}$ de 05 de novembro de 2001. Transfere ao domínio dos Estados de Roraima e do Amapá terras pertencentes à União e dá outras providências. Disponível em: বttp:// www.planalto.gov.br/ccivil_03/leis/LEIS_2001/L10304.htm>. Acesso em 10 jan. 2016. BRASIL. Lei no $\mathbf{1 2 . 6 5 1}$ de 25 de maio de 2012. Dispõe sobre a proteção da vegetação nativa; altera as Leis $\mathrm{n}^{-5}$ 6.938, de 31 de agosto de 1981, 9.393, de 19 de dezembro de 1996, e 11.428, de 22 de dezembro de 2006; revoga as Leis $n^{05} 4.771$, de 15 de setembro de 1965, e 7.754, de 14 de abril de 1989, e a Medida Provisória n-2.166-67, de 24 de agosto de 2001; e dá outras providências. Disponível em: বhttp://www.planalto.gov.br/ccivil_03/_ato20112014/2012/lei//12651.htm>. Acesso em 12 jan. 2016.

BARRAGÁN, J. Ordenacion, planificacion y gestion del espacio litoral. Barcelona: Tau, 1993. BORDO, A., (2009). As diferentes abordagens do conceito de território. Faculdade de Ciências Contábeis e de Administração do Vale do Juruena. Disponível em: বhttp://www.ajes.edu. br/arquivos/20090417110045.pdf>. Acesso em 10 jan. 2016 
CARVALHO, T.M.; CARVALHO, C.M. MORAIS, R.P. Fisiografia da paisagem e aspectos biogeomorfológicos do lavrado, Roraima, Brasil. Revista Brasileira de Geomorfologia, v.17, p.94 $107,2016$.

CARVALHO, T.M. SÍNTESE DOS ASPECTOS HIDROGEOMORFOLÓGICOS DO ESTADO DE RORAIMA, BRASIL. In:Contribuições à Geologia da Amazônia(Orgs. Gorayeb, P.; M eiguins, A.). Edição Volume 9 (9CGA), Ed. SBG-Norte. 2015, p.435-450.

CARVALHO, T.M. Sistemas e Ambientes Denudacionais e Agradacionais, uma primeira aproximação para o Estado de Roraima, Norte da Amazônia. Revista Acta Geográfica, v.8, n.16, p.77-98, 2014.

CARVALHO, T.M .; M ORAIS, R.P. Aspectos hidrogeomorfológicos do sistema fluvial do baixo rio Uraricoera e alto rio Branco como subsídio à gestão de terras. Geografias, v.10, n.2, p.118135, 2014.

COM ISSÃO do ZEE percorrerá interior de Roraima para colher sugestões. Jornal Folha de Boa Vista, 16 dezembro 2015. Disponível em: বttp://www.folhabv.com.br/noticia/Comissao-doZEE-percorrera-interior-de-Roraima-para-colher-sugestoes-/12368>. Acesso em 28 jan. 2016. COM ISSÃO vai apurar indícios de irregularidades em contrato. Jornal Folha de Boa Vista, 07 janeiro 2016. Disponível em: বttp:// www.folhabv.com.br/noticia/Comissao-vai-apurar-indici os-de-irregularidades-em-contrato/12858. Acesso em 15 jan. 2016.

DALLABRIDA, V. R. A gestão territorial através do diálogo e da participação. IX Coloquio Internacional de Geocrítica. Porto Alegre: UFRGS, 2007.

FLORES, M. (2006). A identidade cultural do território como base de estratégias de desenvolvimento - uma visão do Estado da arte. Disponível em: 〈http://www.rimisp.org/getdoc. php? docid $=3736>$. Acesso em 18 jan.2016.

FRANCO, E. M.S., Del'Arco, J.O., Rivetti, M. 1975. Capítulo II Geomorfologia. Folha NA.20 Boa Vista e parte das folhas NA.21 Tumucumaque, NB.20 Roraima e NB.21. In: Radam Brasil, Levantamento de Recursos Naturais. DNPM, Projeto Radam Brasil, Rio de Janeiro, RJ. 137$180 \mathrm{p}$.

GESTÃO TERRITORIAL. Visões e significados. Disponível em: বhttps://www.academia.edu/ 2052742/Gest\%C3\%A30_Territorial_Vis\%C3\%B5es_e_significados>. Acesso em 20 jan.2016.

INSTITUTO BRASILEIRO D̄E GEOGRĀFIA E ESTATÍSTICA. Estimativas de população. Disponível em: বtp://ftp.ibge.gov.br/Estimativas_de_Populacao/Estimativas_2015/estimativa_dou_201 5_20150915.pdf>. Acesso em 20 jan.2016.

MINISTÉRIO DO M EIO AM BIENTE. Gestão territorial. Zoneamento Ecológico-Econômico. Disponível em: 〈http://www.mma.gov.br/gestao-territorial/zoneamento-territorial>. Acesso em 20 jan. 2016.

MORAIS, R. P.; CARVALHO, T.M. Aspectos Dinâmicos da Paisagem do Lavrado, Nordeste de Roraima. Revista Geociências, v. 34, n.1, p. 55-68, 2015.

RAFFESTIN, Claude. Por uma geografia do poder. Tradução de Maria Cecília França. São Paulo: Ática, 1993. Disponível em: বhttp://www.univale.br/cursos/tipos/pos-graduacao_strictu_ sensu/mestrado_em_gestao_integrada_do_territorio/_downloads/por_uma_geografia_do_ poder-claude_raffestin.pdf $>$. Acesso em 15 jan. 2016. 
RORAIM A. 0 Brasil do Hemisfério Norte: Diagnóstico Científico e Tecnológico para o Desenvolvimento. Roraima: Ambtec, 1994.

RORAIM A. Lei Complementar no 143 de 15 de janeiro de 2009. Institui o Sistema de Planejamento e Ordenamento Territorial do Estado de Roraima e dá outras providências. Disponível em: \ttp://www.tjrr.jus.br/legislacao/phocadownload/LeisComplementaresEstaduais/ 2009/Lei_Comp_Est_143-2009.pdf>. Acesso em 16 jan. 2016.

RORAIM $\bar{A}$. Lei Complementar no 144 de 06 de março de 2009. Dá nova redação ao §3음o art. 16 e ao §3 do art. 17 da Lei Complementar no 143, de 15 de janeiro de 2009, que institui o Sistema de Planejamento e Ordenamento Territorial do Estado de Roraima e dá outras providências. Disponível em: ঝttp://www.al.rr.leg.br/leis/leis-complementares/2009/viewdown load/71-2009/1811-lei-complementar-n-144-de-06-de-marco-2009>. Acesso em 16 jan. 2016. SANTOS, M. Espaço e Método. São Paulo: Nobel, 1995.

UNIVERSIDADE FEDERAL DO CEARÁ. Biblioteca Universitária. Guia de Normalização de Trabalhos Acadêmicos da UFC. Disponível em: বttp:// www.biblioteca.ufc.br/images/arquivos/d ocumentos_tecnicos/guia_normalizacao_trabalhos_ufc_2013.pdf >. Acesso em: 10 mar. 2016. UNIVERSIDĀDE FEDERAL DE RORAIM A. Cartilha síntese da proposta do ZEE/ RR para consulta pública ( 2 a atualização). Disponível em: 〈http://ufrr.br/mepa/phocadownload/cartilha\%20ze e-rr\%20-\%20versao\%20final\%20_1_.pdf>Acesso em: 10 mar. 2016.

VANZOLINI, P.E., Carvalho, C.M. Two sibling and sympatric species of Gymnophthalmus in Roraima, Brasil (Sauria:Teiidae). Papéis Avulsos de Zoologia, São Paulo, 1991, 37(12):173226.

Artigo recebido em 26 de agosto de 2016.

Aprovado em 31 de dezembro de 2016. 